University of Wollongong

Research Online

Australian Institute for Innovative Materials -

Papers

Australian Institute for Innovative Materials

$1-1-2019$

Continuous carbon nanotube composite fibers for flexible aqueous lithiumion batteries

Tao Zhang

Tianjin University

Shuaishuai Han

Tianjin University

Wenlei Guo

Tianjin University

Feng Hou

Tianjin University

Jiachen Liu

Tianjin University

See next page for additional authors

Follow this and additional works at: https://ro.uow.edu.au/aiimpapers

Part of the Engineering Commons, and the Physical Sciences and Mathematics Commons

Research Online is the open access institutional repository for the University of Wollongong. For further information contact the UOW Library: research-pubs@uow.edu.au 


\title{
Continuous carbon nanotube composite fibers for flexible aqueous lithium-ion batteries
}

\author{
Abstract \\ Continuous composite fibers have been obtained by online modifying the direct-spun carbon nanotube \\ (CNT) fibers with active materials (LiFePO 4 or LiTi 2 PO 4 ) through dipping and twisting. The composite \\ fibers exhibit high specific capacity and good rate performance for an aqueous lithium-ion battery with 1 \\ M Li 2 SO 4 electrolyte, due to the fast electron transport arising from the close contact between the \\ active materials and CNTs. A flexible fiber-shaped aqueous lithium-ion battery fabricated from the \\ composites can deliver a high specific capacity of $29.1 \mathrm{mAh} \mathrm{g-1}$ at a current density of $0.25 \mathrm{Ag}-1$ and a \\ high energy density of $30.12 \mathrm{Wh} \mathrm{kg}-1$, showing the great potential of the composite fibers for \\ applications in flexible energy storage devices.

\section{Disciplines} \\ Engineering | Physical Sciences and Mathematics

\section{Publication Details} \\ Zhang, T., Han, S., Guo, W., Hou, F., Liu, J., Yan, X., Chen, S. \& Liang, J. (2019). Continuous carbon nanotube \\ composite fibers for flexible aqueous lithium-ion batteries. Sustainable Materials and Technologies, 20 \\ (17), e00096-1-e00096-6.
}

\section{Authors}

Tao Zhang, Shuaishuai Han, Wenlei Guo, Feng Hou, Jiachen Liu, Xiao Yan, Shunquan Chen, and Ji Liang 


\section{Continuous Carbon Nanotube Composite Fibers for Flexible}

\section{Aqueous Lithium-ion Batteries}

Tao Zhang, ${ }^{a}$ Shuaishuai Han, ${ }^{\text {a }}$ Wenlei Guo, ${ }^{\text {a }}$ Feng Hou,${ }^{\mathrm{a}} *$ Jiachen Liu, ${ }^{\mathrm{a}}$ Xiao Yan,,${ }^{\mathrm{b}} *$ Shunquan Chen, ${ }^{\mathrm{b}}$ and Ji Liang ${ }^{\mathrm{c},} *$

${ }^{a}$ Key Laboratory of Advanced Ceramics and Machining Technology of Ministry of Education, School of Materials Science and Engineering, Tianjin University. Tianjin 300072, P. R. China

${ }^{\mathrm{b}}$ Guangdong Key Laboratory of Membrane Materials and Membrane Separation, Guangzhou Institute of Advanced Technology, Chinese Academy of Sciences, Guangzhou 511458, P. R. China

c Institute for Superconducting \& Electronic Materials, Australian Institute of Innovative Materials, The University of Wollongong, Innovation Campus, North Wollongong, NSW 2500, Australia

*Corresponding authors: Feng Hou (houf@tju.edu.cn), Xiao Yan (xiao.yan@giat.ac.cn), and Ji Liang (liangj@uow.edu.au) 


\begin{abstract}
Continuous composite fibers have been obtained by online modifying the direct-spun carbon nanotube $(\mathrm{CNT})$ fibers with active materials $\left(\mathrm{LiFePO}_{4}\right.$ or $\left.\mathrm{LiTi}_{2} \mathrm{PO}_{4}\right)$ through dipping and twisting. The composite fibers exhibit high specific capacity and good rate performance for an aqueous lithium-ion battery with $1 \mathrm{M} \mathrm{Li}_{2} \mathrm{SO}_{4}$ electrolyte, due to the fast electron transport arising from the close contact between the active materials and CNTs. A flexible fiber-shaped aqueous lithium-ion battery fabricated from the composites can deliver a high specific capacity of $29.1 \mathrm{mAh} \mathrm{g}^{-1}$ at a current density of $0.25 \mathrm{~A} \mathrm{~g}^{-1}$ and a high energy density of $30.12 \mathrm{Wh} \mathrm{kg}^{-1}$, showing the great potential of the composite fibers for applications in flexible energy storage devices.
\end{abstract}

Keywords: Floating CVD; Carbon nanotube composite fibers; Flexible; Aqueous lithium-ion batteries 


\section{Introduction}

Wearable devices and electronics have called for increasing demands on flexible energy storage devices and attracted widespread research attention. Flexibility is essential for designing wearable devices since the devices will be repeatedly stretched and bent during use. Traditional energy storage devices, such as the commercially available supercapacitors and lithium-ion batteries (LIBs), are typically inflexible because of the rigid nature of the stacking structure of their electrodes, which hinders their applications for wearable devices. Therefore, flexible electrodes are critical for the development of novel energy storage devices. According to the different structures, flexible electrodes can be divided into three types: bulk electrodes, film electrodes, and fiber electrodes. ${ }^{1}$ The bulk electrodes are still in the laboratory research stage, and the technical conditions are not mature by far. ${ }^{2,3}$ The film electrodes include substrate supported electrodes and self-supported electrodes. However, the former has the conductivity and energy density problems ${ }^{4,5}$ while the latter suffers from poor mechanical strength and efficiency problems, ${ }^{6,7}$ respectively. Amongst all the candidates, fibrous materials are most promising because of their unique advantages, including lightweight, good flexibility and portability, and high specific surface area. ${ }^{8}$ Moreover, fiber-based energy storage devices can be easily integrated into various other devices, such as smart clothes and flexible electronics, and therefore are considered an ideal energy supply for wearable devices. ${ }^{9}$

Fiber-shaped LIBs integrate the typical components of LIBs, such as the current collector, active materials, and electrolyte, which are assembled into a 
one-dimensional structure. Such LIBs can be further assembled into a parallel structure, a helical structure, and/or a coaxial structure, if necessary. ${ }^{10}$ However, the complex structures can result in a large weight, which is unfavorable for practical applications in wearable devices. Therefore, the highly conductive, lightweight, and flexible carbon nanotube (CNT) fibers have become a promising and popular scaffold material for flexible devices without the need to use binders or other additives. After integrating the fibers with different active species, the obtained composite fiber electrodes can be directly used in various energy storage/conversion fields. ${ }^{11,12}$ By far, the composite CNT-based fiber electrodes include $\mathrm{CNT} / \mathrm{MnO}_{2}$ fibers, ${ }^{13} \mathrm{CNT} / \mathrm{Si}$ fibers, ${ }^{14} \mathrm{CNT} / \mathrm{Li}_{4} \mathrm{Ti}_{5} \mathrm{O}_{12}$ fibers, $\mathrm{CNT} / \mathrm{LiMn}_{2} \mathrm{O}_{4}$ fibers, ${ }^{15} \mathrm{CNT} /$ polyimide fibers. ${ }^{16}$ The fiber-shaped LIBs assembled with these composite fibers have been woven into cloth or other textiles.

At present, there are three major methods to prepare CNT fibers: wet spinning, ${ }^{17}$ array drawing, ${ }^{18}$ and gas phase spinning. ${ }^{19}$ The wet spinning process requires pretreatment of the CNTs to form a liquid suspension, which is time-consuming and involves harsh/hazardous treatments. Using the array drawing method, one can directly spin fibers from vertically-aligned CNT arrays by utilizing the van der Waals force between the CNTs. However, the fiber lengths are strictly restricted by the size of the arrays and other processing parameters. Therefore these two approaches are unsuitable for large-scale fabrication of composite fibers.

In contrast, continuous CNT fibers can also be directly spun from an aerogel of high-quality CNTs in the gas phase spinning method. The resulted CNT fibers exhibit 
outstanding mechanical strength and electrical conductivity due to the length of the CNTs (1 mm or more) and the flattened nature of the double-walled nanotubes. ${ }^{19}$ Consequently, compositing the active species with such CNT fibers can be expected to result in highly flexible and conductive composite fiber electrodes, which are highly desirable for fiber LIBs and can be continuously produced at a larger scale.

On the other hand, aqueous LIBs have can be manufactured under ambient conditions, therefore, are relatively low in cost, environmentally friendly, and much safer in comparison with the ones with flammable organic electrolytes. ${ }^{20}$ As a result, assembling an aqueous fiber LIB using the above-mentioned composite fibers can be expected to possess the merits of both high flexibility and excellent safety, making them especially suitable for wearable application. Moreover, these advantages can be further strengthened regarding the readiness of such CNT fibers for large scale fabrication.

On the basis of these considerations, we herein report a very simple and scalable protocol to fabricate flexible and aqueous LIBs that are based on CNT fiber composite electrodes. The CNT fibers were directly spun through a floating catalyst chemical vapor deposition process and subsequently online modified with cathode/anode active materials (i.e., $\mathrm{LiFePO}_{4}$ and $\mathrm{LiTi}_{2}\left(\mathrm{PO}_{4}\right)_{3}$, respectively) of LIBs. The prototype fiber LIB that was assembled with these fiber electrodes showed a very stable yet high specific capacity of $29.1 \mathrm{mAh} \mathrm{g}^{-1}$ at a current density of $0.25 \mathrm{~A} \mathrm{~g}^{-1}$, upon various bending conditions, corresponding to a moderate energy density of $30.12 \mathrm{Wh} \mathrm{kg}^{-1}$, further confirming the suitability of these CNTs-based electrodes for 
flexible energy storage applications.

\section{Experimental}

\subsection{Fabrication of materials}

Continuous CNT fibers were fabricated by the floating-catalyst chemical vapor deposition (CVD) method and direct spun from the high-temperature zone of the vertical reaction chamber $\left(1180{ }^{\circ} \mathrm{C}\right)$, using ethanol as the carbon precursor, ferrocene (1.7 wt.\%) as the catalyst, and thiophene (1.6 wt.\%) as the promoter. ${ }^{21}$ The precursor solution was injected from the upper end of the chamber at a rate of $8 \mathrm{ml} \mathrm{min}{ }^{-1}$. Under the hydrogen flow rate of $1200 \mathrm{sccm}$, CNTs were formed and self-assembled into aerogel at the hot zone of the chamber, which was then drawn out from the lower end of the chamber and through the water seal the to form high-performance CNT fibers.

$\mathrm{LiFePO}_{4}$ (LFP, purchased from Pulead Technology Industry Co., Ltd.) particles were dispersed in ethanol to form a $5 \mathrm{mg} \mathrm{ml}^{-1}$ suspension. Carbon-coated $\mathrm{LiTi}_{2}\left(\mathrm{PO}_{4}\right)_{3}$ (LTP) was prepared by the spray-drying and sintering process. ${ }^{22}$ Firstly, $\mathrm{Li}_{2} \mathrm{CO}_{3}$, $\mathrm{NH}_{3} \mathrm{H}_{2} \mathrm{PO}_{4}$, and $\mathrm{TiO}_{2}$ were added to $100 \mathrm{ml}$ of $2 \mathrm{wt} \%$ polyvinyl alcohol aqueous solution. Then the solution was spray dried and the obtained composite precursor powder was heated at $900{ }^{\circ} \mathrm{C}$ for $12 \mathrm{~h}$ under a nitrogen atmosphere to achieve carbon-coated LTP. The amount of the coated carbon in the product was about 15 wt.\%. The resulted LTP was also dispersed in ethanol, forming a $5 \mathrm{mg} \mathrm{ml}^{-1}$ suspension.

Continuous composite fiber electrodes were achieved using an online post-processing method. Specifically, in the spinning process, the CNT fibers traveled 
through in the suspension of the active materials, which was kept under ultrasonication to ensure the homogeneous dispersion in the process, to be loaded with the LFP or LTP. Afterward, the composite fibers were twisted before drying to avoid possible detachment of the active materials and to enhance the contact between the CNTs and the active materials.

\subsection{Characterization}

Scanning electron microscope (SEM, Hitachi, S4800) and transmission electron microscope (TEM, Tecnai G2 F20, FEI, Holland) were applied for morphological and structural analysis. The crystalline structures of the materials were analyzed by X-ray diffraction (XRD, Rigaku D/Max-2500) and Raman spectra (Renishaw, Lab RAM HR800). The electronic conductivity of the materials was tested on a multimeter, and the tensile property was assessed on a tensile tester (XQ-1, Donghua UVI) under a drawing speed of $10 \mathrm{~mm} \mathrm{~s}^{-1}$ with a $10 \mathrm{~mm}$ clamp.

\subsection{Electrochemical measurements}

The electrochemical performance of the composite fiber electrodes was tested on an electrochemical workstation (CHI 660D, Chenhua, Shanghai) equipped with a three-electrode cell. The performance of the composite fibers was tested by using them as the working electrode, an $\mathrm{Ag} / \mathrm{AgCl}$ electrode as the reference electrode, and an activated carbon electrode as the counter electrode. All the three electrodes were immersed in an aqueous solution containing $1 \mathrm{M} \mathrm{Li}_{2} \mathrm{SO}_{4}$. The cyclic voltammetry (CV) at different scan rates $\left(1,5\right.$, and $\left.10 \mathrm{mV} \mathrm{s}^{-1}\right)$ and galvanostatic charge/discharge (GCD) tests at various rates were carried out. The full-battery performance was firstly 
tested in a two-electrode cell with LFP/CNT composite fibers as the cathode, LTP/CNT composite fibers as the anode, and $1 \mathrm{M} \mathrm{Li}_{2} \mathrm{SO}_{4}$ aqueous solution as the electrolyte. Both fiber electrodes were immersed in the electrolyte to simulate a battery. Argon was purged to vent oxygen during the test.

A prototype fiber LIB was then assembled using the two types of fiber electrodes and a gel electrolyte. The gel electrolyte was prepared as followed: $3 \mathrm{~g}$ of sodium carboxymethyl cellulose (CMC) was dissolved in $60 \mathrm{ml}$ of deionized (DI) water and stirred at $80{ }^{\circ} \mathrm{C}$ for $3 \mathrm{~h}$ to form a gel. $14.6 \mathrm{~g}$ of $\mathrm{Li}_{2} \mathrm{SO}_{4} \cdot \mathrm{H}_{2} \mathrm{O}$ was dissolved in $36 \mathrm{ml} \mathrm{DI}$ water and then added into the CMC gel with stirring for $1 \mathrm{~h}$ to form the $\mathrm{CMC} / \mathrm{Li}_{2} \mathrm{SO}_{4}$ gel electrolyte. Two composite fibers were coated with the gel electrolyte and placed in a parallel manner to form a fiber-shaped aqueous LIB. GCD tests were conducted at different current densities and forms of bending. The cycling performance of the battery was studied at a current density of $0.5 \mathrm{~A} \mathrm{~g}^{-1}$.

Here, the capacity can be calculated from the charge/discharge curves according to the following equation (1):

$$
\mathrm{C}=\frac{I \times \Delta t}{m}
$$

where $\mathrm{C}$ is the capacity $\left(\mathrm{mAh}^{-1}\right), I$ is the discharge current $(\mathrm{A}), \Delta \mathrm{t}$ is the discharge time (s), and $m$ is the mass of active materials ( $\mathrm{g}$ )

The energy density and power density of the battery were calculated according to the following equations (2) and (3): 


$$
\begin{gathered}
\mathrm{E}=\frac{I \int V d t}{m} \\
\mathrm{P}=\frac{E}{t}
\end{gathered}
$$

where $\mathrm{E}$ is the energy density $\left(\mathrm{Wh} \mathrm{kg}^{-1}\right), \mathrm{P}$ is the power density $\left(\mathrm{W} \mathrm{kg}^{-1}\right), I$ is the discharge current (A), $V$ is the potential window $(\mathrm{V}), t$ is the discharge time (s), and $m$ is the mass of active materials $(\mathrm{g})$.

\section{Results and discussion}

CNT fibers can be spun uninterruptedly at a kilometer-length using this floating-catalyst CVD process, ${ }^{21}$ which is exceptionally convenient for industrial-scale production. The resulted CNT fibers are $100 \mu \mathrm{m}$ in diameter after being twisted at $30^{\circ}$ (Fig. 1a). The surface of the fibers is dense, which can be attributed to the water densification effect during the drawing process and the capillary force due to the water evaporation in the subsequent drying process. ${ }^{21}$ There are also some voids on the surface of the CNT fibers, which could facilitate the loading of active materials (Fig. 1b).

The fine structures of the materials were further studied under TEM. Individual CNTs contact with each other to form bundles, which are interconnected to form a conductive network. The diameter of the bundles is usually smaller than $100 \mathrm{~nm}$ (Fig. 1c). Individual CNTs are mainly double-walled, with a diameter of $\sim 5 \mathrm{~nm}$ (Fig. 1d). 

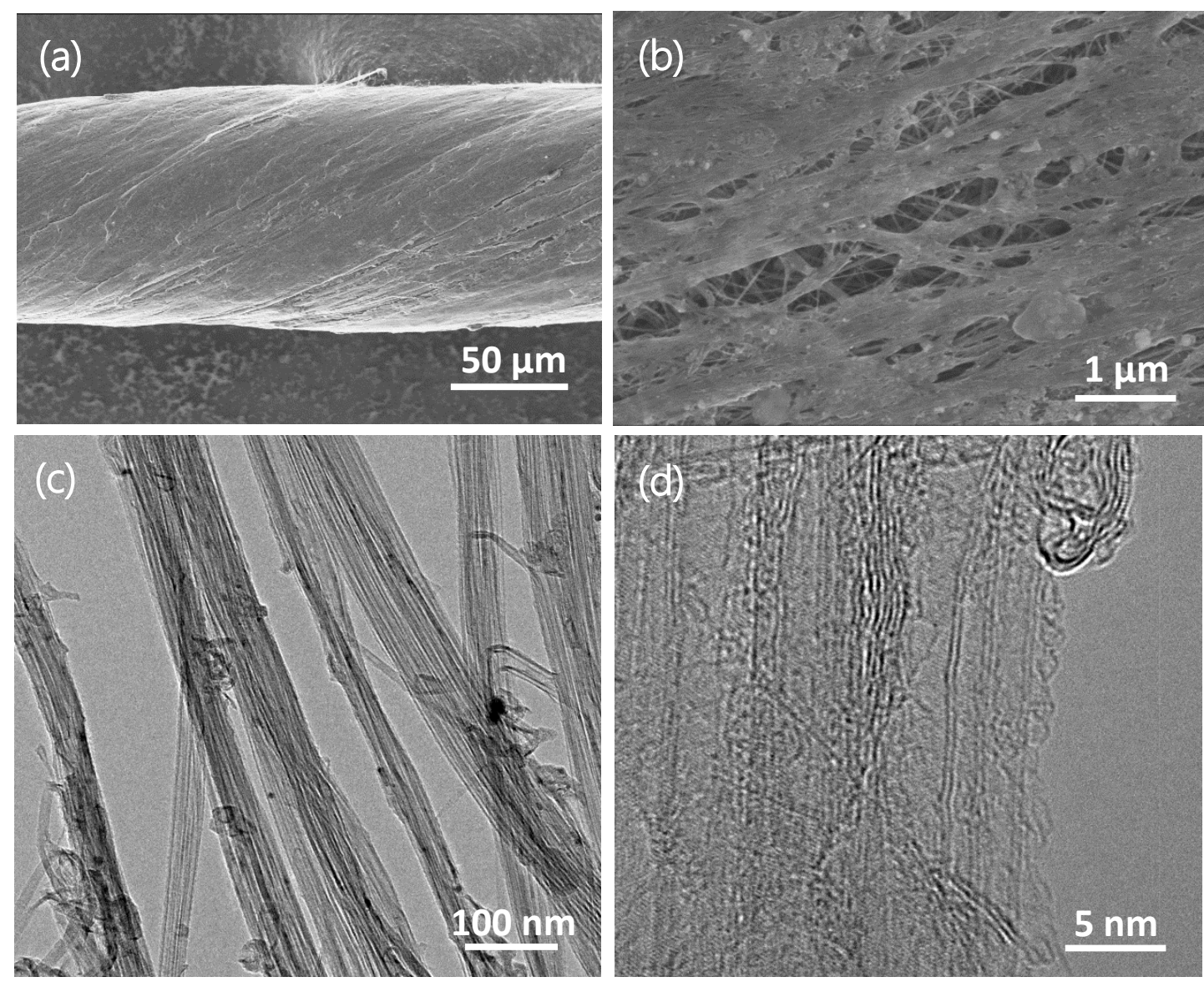

Fig. 1. Microstructures of pure CNT fibers. (a) and (b) SEM images of the surface of CNT fibers; (c) and (d) TEM images of CNT fibers.

More structural information can be revealed in the Raman spectra. A strong peak located at $1573 \mathrm{~cm}^{-1}$ and a weak peak located at $1342 \mathrm{~cm}^{-1}$ can be attributed to the $\mathrm{G}$ band and D band, respectively. The $\mathrm{G}$ band reflects the order of carbon atoms alignment, due to the axial tensile vibration of the $\mathrm{C}=\mathrm{C}$ bond. The $\mathrm{D}$ band reflects the disorder of carbon atoms, caused by amorphous carbon and structural defects in CNTs. The pristine CNT fibers have a very low $\mathrm{I}_{\mathrm{D}} / \mathrm{I}_{\mathrm{G}}$ ratio of 0.24 , indicating its well-graphitized structure that is highly desirable for achieving the high mechanical 
performance and excellent electronic conductivity (Fig. S1). The mechanical properties of the material were obtained by the tensile test. The stress-strain curve progresses smoothly under tension without fluctuations, suggesting no significant structural defects in the fibers. At the beginning of the stress-strain curve, the strain increases significantly with increased stress. This process corresponds to the CNT fiber drawing stage. Then, as the stress increases, the strain increase trend gradually becomes slower. Finally, the CNT fibers break abruptly. The tensile strength of the CNT fibers is $330 \mathrm{MPa}$ with a strain of $9.5 \%$ (Fig. S2). Such mechanical performance can meet the flexibility requirement, enabling them to withstand bending, twisting, and weaving.

The LFP and LTP particles, as cathode and anode active materials of LIBs, are also well crystallized, as confirmed by XRD (Fig. S3). These active materials also have small particle sizes, typically less than $500 \mathrm{~nm}$ (Fig. S4). It can be seen from the TEM images that the LFP particles have irregular shape with a particle size of $100 \mathrm{~nm}$ to 200nm, and the C/LTP particles have an approximately circular shape with a particle diameter between $100 \mathrm{~nm}$ and $200 \mathrm{~nm}$, making them possible to be loaded inside the fibers. Continuous composite fibers were fabricated by immersing the CNT fibers into the ethanol suspension of active materials and subsequent drying. By weighing continuous fibers and composite fibers, the loading of LFP is about $0.60 \mathrm{mg}$ $\mathrm{m}^{-1}$, and the loading of LTP is about $0.67 \mathrm{mg} \mathrm{m}^{-1}$. And the loading amount of the active materials are 65 wt. $\%$ and 72 wt. $\%$ for LFP/CNT and LTP/CNT composite fibers, respectively. The flexibility of the CNT fibers has been largely retained after 
the loading of active materials.

The structures of the composite fibers are firstly observed under SEM (Fig. 2). The diameters of LFP/CNT and LTP/CNT composite fibers are $95 \mu \mathrm{m}$ and $110 \mu \mathrm{m}$, which are close to that of pure CNT fibers (Fig. 2a, c). As shown in Fig. 2b, d, the active material particles are embedded on the CNT networks, and they are in close contact. As a result, the electronic conductivity of the composite fiber is only slightly increased after the loading of LFP/LTP, which can ensure the efficient electron transport during the operation of batteries (Fig. S5).
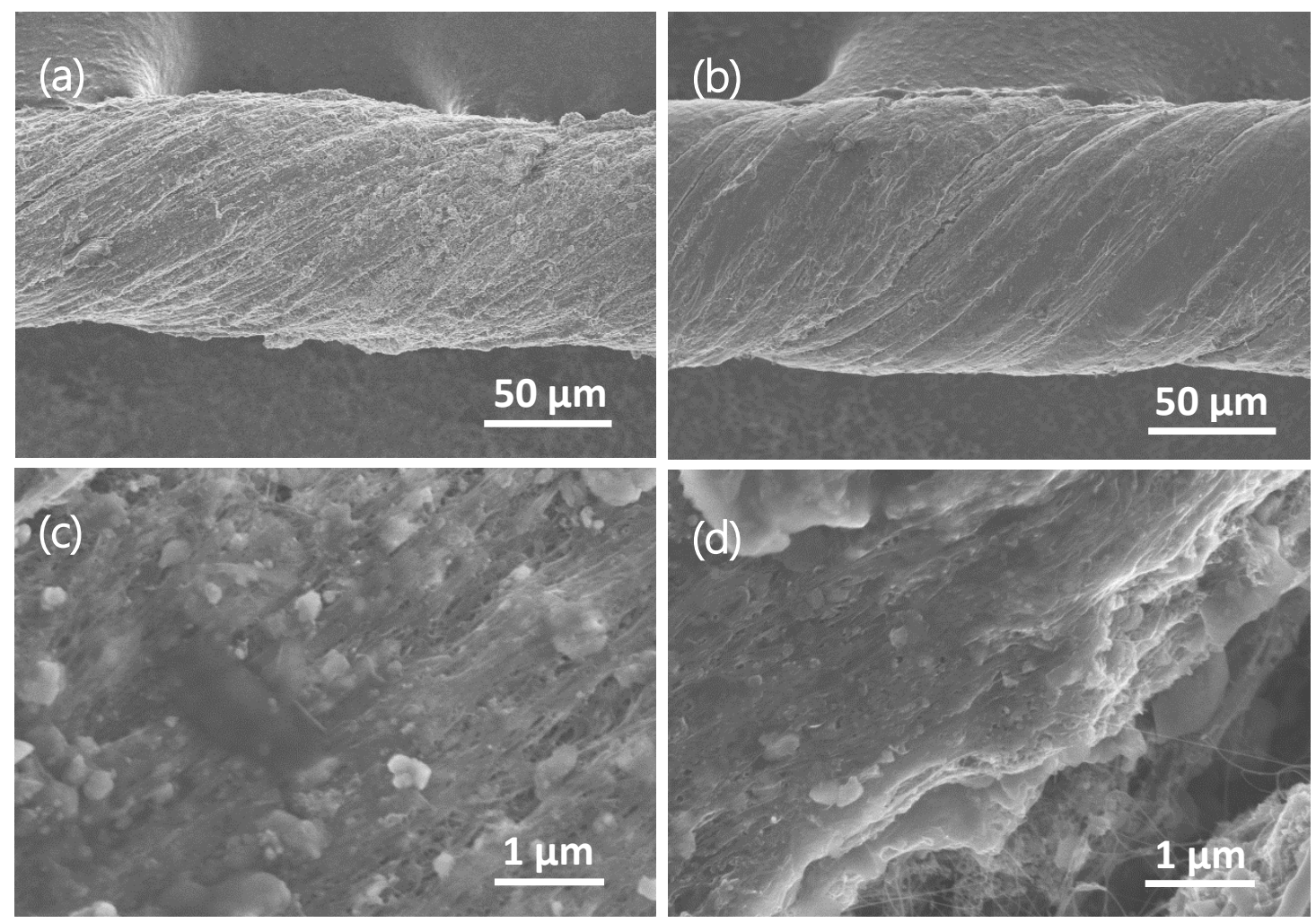

Fig. 2. SEM images of composite fibers. LFP/CNT composite fibers at low (a) and high (c) magnification; LTP/CNT composite fibers at low (b) and high (d) magnification.

The electrochemical performance of the LFP/CNT composite fibers and 
LTP/CNT composite fibers in aqueous electrolyte were firstly investigated by CV and GCD in a three-electrode system (Fig. 3). In the CV profile of the LFP/CNT composite fibers, a pair of redox peaks can be seen at $0.0 \mathrm{~V}$ and $0.4 \mathrm{~V}$, which corresponds to the Li ion intercalation/deintercalation in the LFP (Fig. 3a and Fig S6). As for the LTP/CNT composite fibers, a pair of redox peaks at $-0.8 \mathrm{~V}$ and $-0.76 \mathrm{~V}$ can be noticed in the $\mathrm{CV}$ profile. It can also be seen from the CV curves that the peak current gradually increased as the scan rate is increased, which might arise from the capacitance contribution of the composite fibers (Fig. S6). As shown in Fig. 3b, the capacity of LFP/CNT composite fibers are 64.1, 56.8, $43.5 \mathrm{mAh} \mathrm{g}^{-1}$ (calculated based on the weight of the whole electrode) at the rates of $0.5,1.0,2.0 \mathrm{~A} \mathrm{~g} \mathrm{~g}^{-1}$, respectively. As for the LTP/CNT composite fibers, a pair of redox peaks at $-0.8 \mathrm{~V}$ and $-0.76 \mathrm{~V}$ can be noticed on the CV profile (Fig. 3c). For these anode fibers, the capacities are 78.4, 67.3, 41.2 $\mathrm{mAh} \mathrm{g}^{-1}$ at the current densities of $0.5,1.0,2.0 \mathrm{~A} \mathrm{~g}^{-1}$, respectively (Fig. 3d). 

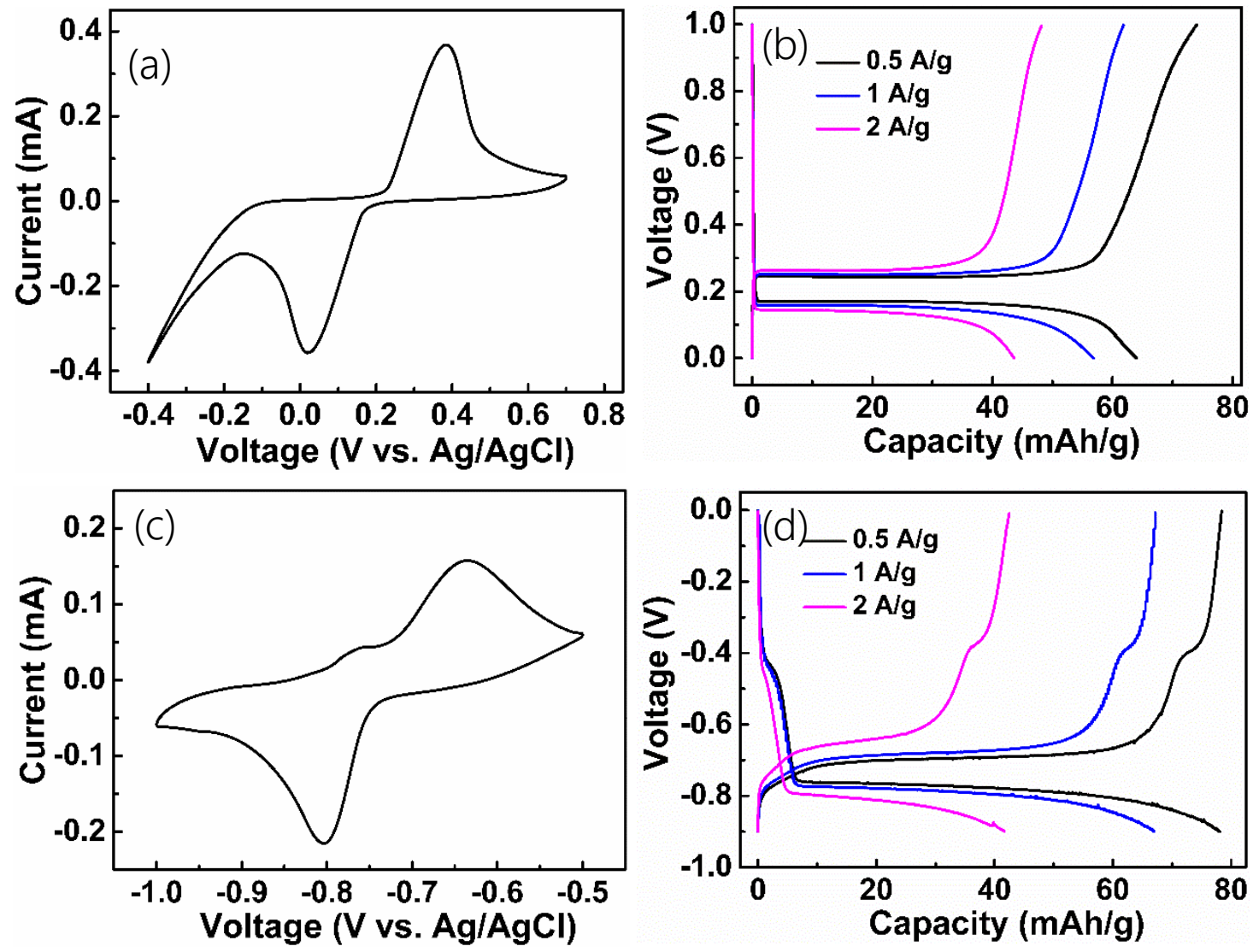

Fig. 3. Electrochemical performance of composite fibers in $1 \mathrm{M} \mathrm{Li}_{2} \mathrm{SO}_{4}$ solution. (a) Cyclic voltammograms within the potential window $-0.4 \mathrm{~V}$ to $0.7 \mathrm{~V}$ at a scan rate of $1 \mathrm{mV} \mathrm{s}^{-1}$ and (b) Galvanostatic charge/discharge curves within the potential window $0 \mathrm{~V}$ to $1.0 \mathrm{~V}$ at different current densities of LFP/CNT fibers; (c) Cyclic voltammograms within the potential window -1.0 $\mathrm{V}$ to $-0.5 \mathrm{~V}$ at a scan rate of $1 \mathrm{mV} \mathrm{s}^{-1}$ and (d) Galvanostatic charge/discharge curves within the potential window $-0.9 \mathrm{~V}$ to $0 \mathrm{~V}$ at different current densities of LTP/CNT composite fibers.

Then, a simulated aqueous cell was first assembled with LFP/CNT composite fibers as the positive electrode, LTP/CNT composite fibers as the negative electrode, and $1 \mathrm{M} \mathrm{Li}_{2} \mathrm{SO}_{4}$ solution as the electrolyte. Its electrochemical performance was evaluated using CV and GCD (Fig. 4). Obvious redox peaks can be seen within the 
potential region 0 to $1.3 \mathrm{~V}$ in the $\mathrm{CV}$ profile (Fig. $\mathbf{4 a}$ ). Fig. $\mathbf{4 b}$ shows the GCD curves of the cell at different current densities $\left(0.2,0.5,1.0 \mathrm{~A} \mathrm{~g}^{-1}\right)$ within the potential region from 0 to $1.3 \mathrm{~V}$. The plateaus of the full cell are at $0.8 \mathrm{~V}$ for discharge and $1.0 \mathrm{~V}$ for charge, respectively, in accordance with the potential difference of redox peaks of composite fibers. The small peak at $0.5 \mathrm{~V}$ to $0.6 \mathrm{~V}$ in the $\mathrm{CV}$ curve and the corresponding charge/discharge platforms in GCD curves should be caused by the $\mathrm{TiPO}_{4}$ impurity in $\mathrm{LTP}^{22}$ The following electrochemical reactions occur during charging and discharging of a lithium ion battery:

Cathode charging progress:

$$
\mathrm{LiFePO}_{4}-x \mathrm{Li}^{+}-x e^{-} \rightarrow(1-x) \mathrm{LiFePO}_{4}+x \mathrm{FePO}_{4}
$$

Cathode discharging progress:

$$
\mathrm{FePO}_{4}+x \mathrm{Li}^{+}+x e^{-} \rightarrow x \mathrm{LiFePO}_{4}+(1-x) \mathrm{FePO}_{4}
$$

Anode charging progress:

$$
\mathrm{LiTi}_{2}\left(\mathrm{PO}_{4}\right)_{3}+2 x \mathrm{Li}^{+}+2 x e^{-} \rightarrow \mathrm{Li}_{1+2 x} \mathrm{Ti}_{2}\left(\mathrm{PO}_{4}\right)_{3}
$$

Anode discharging progress:

$$
\mathrm{Li}_{1+2 x} \mathrm{Ti}_{2}\left(\mathrm{PO}_{4}\right)_{3}-2 x L i^{+}-2 x e^{-} \rightarrow \mathrm{LiTi}_{2}\left(\mathrm{PO}_{4}\right)_{3}
$$

The carbon nanotube fibers serve as a host for the active material. High electron conductivity and the interconected porous structure of the CNT fibers failiate fast electron transfer and lithium ion transport, yielding excellent electrochemical performance. The battery capacity is $30.2 \mathrm{mAh} \mathrm{g}^{-1}$ at the current density of $0.2 \mathrm{~A} \mathrm{~g}^{-1}$

(Fig. 4b), by calculating based on the overall weight of the two composite fibers. Although the capacity decreases with increasing current density, however, even at a 
much higher current density of $1 \mathrm{~A} \mathrm{~g}^{-1}$, the capacity of $23.7 \mathrm{mAh} \mathrm{g}^{-1}$ can be still obtained (Fig. 4b), which is typical for the aqueous LIBs. ${ }^{23}$
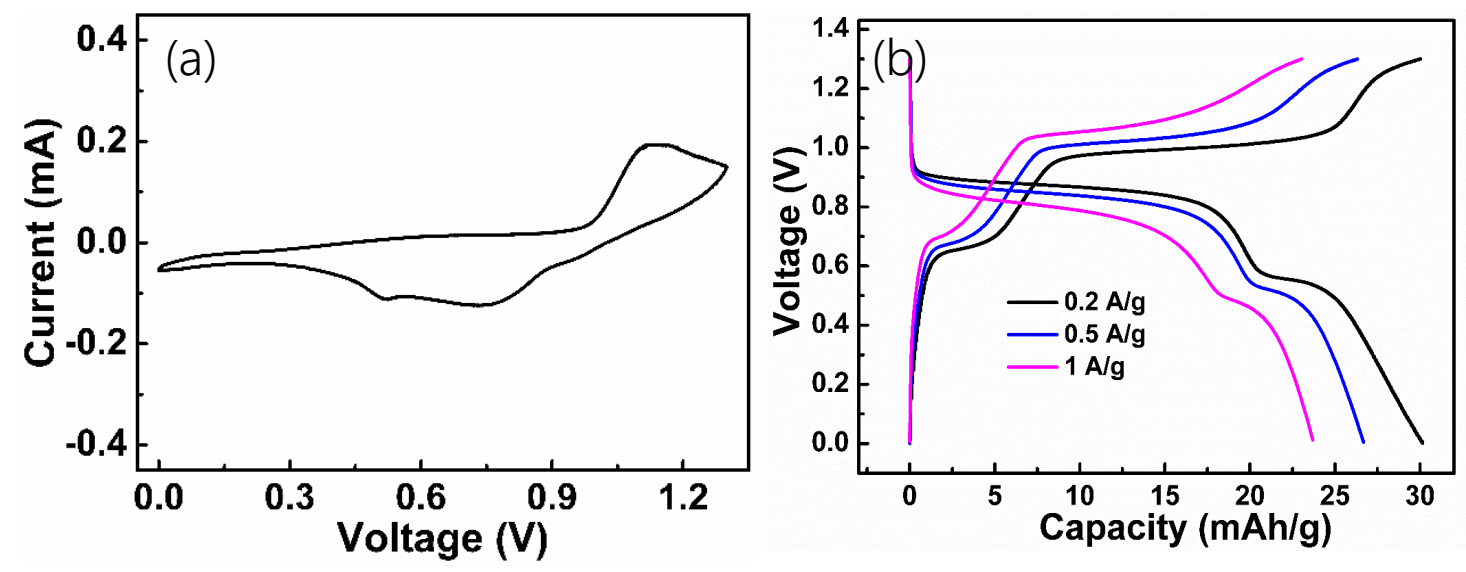

Fig. 4. Electrochemical performance of full cell in $1 \mathrm{M} \mathrm{Li}_{2} \mathrm{SO}_{4}$ solution. (a) Cyclic voltammograms within the potential window $0 \mathrm{~V}$ to $1.3 \mathrm{~V}$ at a scan rate of $5 \mathrm{mV} \mathrm{s}^{-1}$; (b) Galvanostatic charge/discharge curves at different current densities $\left(0.2,0.5,1.0 \mathrm{~A} \mathrm{~g}^{-1}\right)$

Afterward, a flexible fiber-shaped aqueous LIB was fabricated by coating the $\mathrm{CMC} / \mathrm{Li}_{2} \mathrm{SO}_{4}$ gel electrolyte on the composite fibers and assembling them together in a parallel manner. Its electrochemical performance is depicted in Fig. 5. Fig. 5a shows the GCD curves at different current densities $\left(0.25,0.5,1.0 \mathrm{~A} \mathrm{~g}^{-1}\right)$ in the potential region from 0 to $1.3 \mathrm{~V}$. Its charge/discharge profiles are similar to the results of the simulated cell in the $1 \mathrm{M} \mathrm{Li}_{2} \mathrm{SO}_{4}$ aqueous electrolyte. The battery capacity is $29.1 \mathrm{mAh} \mathrm{g}^{-1}$ at $0.25 \mathrm{~A} \mathrm{~g}^{-1}$ and $16.3 \mathrm{mAh} \mathrm{g}^{-1}$ at $1 \mathrm{~A} \mathrm{~g}^{-1}$, based the weight of the two composite fibers, suggesting a reasonably good rate capability considering the quasi-solid battery configuration with a gel electrolyte that has a lower ionic conductivity compared with the aqueous one.

Besides, this fiber-shaped aqueous lithium-ion battery has a high energy density 
of about $30.12 \mathrm{Wh} \mathrm{kg}^{-1}$, which is also typical of fiber-shaped lithium-ion batteries ${ }^{24,25}$ and the film-shaped aqueous lithium-ion battery. ${ }^{23}$ Remarkably, due to the excellent flexibility of the CNT fibers, this battery can also work well under various bending conditions. Even when the battery was bent at $90^{\circ}$, its charge/discharge profiles still remains almost intact, indicating the outstanding flexibility of this fiber-shaped and aqueous LIB (Fig. 5b). The cycling performance of the battery was then evaluated at a current density of $0.5 \mathrm{~A} \mathrm{~g}^{-1}$ for 100 cycles (Fig. 5c). $55 \%$ of the initial capacity can be retained after 100 cycles, which is better than some aqueous lithium-ion batteries, ${ }^{26}$, ${ }^{27}$ but lower than the aqueous lithium-ion battery with LTP as negative materials. ${ }^{28}$ This descending capacity might be attributed to the reaction between active materials and oxygen. ${ }^{29}$ The morphology of the electrode materials after cycling showed no significant change (as shown in Fig. S6). Yet Raman spectra of the composite fibers after cycling revealed a drop in the in the $\mathrm{I}_{\mathrm{D}} / \mathrm{I}_{\mathrm{G}}$ ratio $(\mathbf{F i g}$. S7), indicating that the $\mathrm{Li}$ insertion/deinsertion induces distortion in the graphitic structures of CNT. TEM images of the composite fibers after cycling confirmed that active materials were indeed embedded in the interconnected network of CNT fibers.

From the comparison of the electrochemical performance of the composite fiber battery with other articles (Table $\mathbf{S 1}$ ), the energy density of the composite fiber battery in this work is comparable or even higher with those reported in literature, indicating the feasibility of this method. 

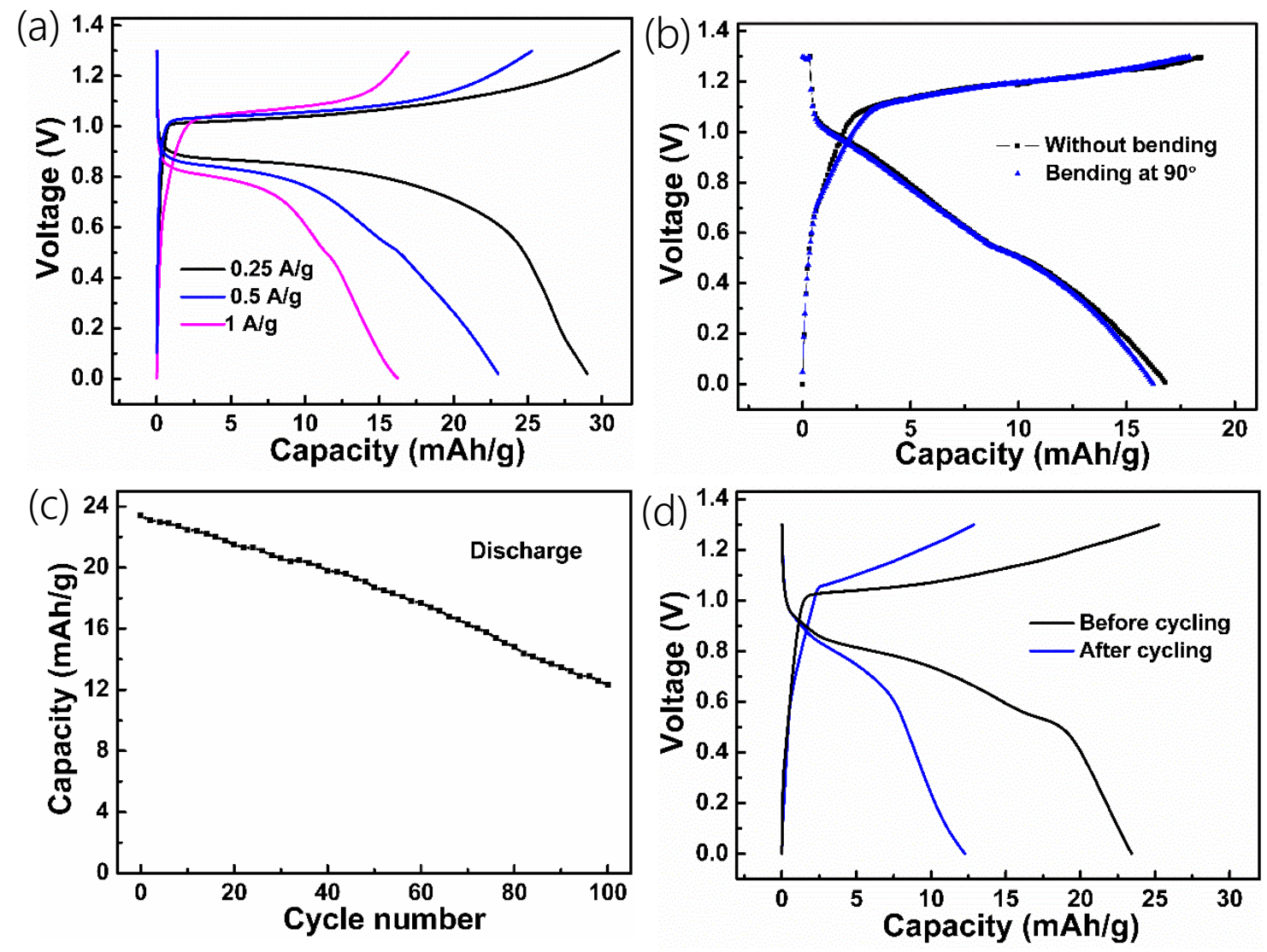

Fig. 5. Electrochemical performance of fiber-shaped Li-ion full cell. (a) Galvanostatic charge/discharge curves at different current densities $\left(0.25,0.5,1.0 \mathrm{~A} \mathrm{~g} \mathrm{~g}^{-1}\right)$; (b) The comparison of Galvanostatic charge/discharge curves of the flexible aqueous LIB before and after bending at a current density of $1 \mathrm{~A} \mathrm{~g}^{-1}$; (c) Cyclic performance of aqueous LIBs at a current density of $0.5 \mathrm{~A}$ $\mathrm{g}^{-1}$; (d) The comparison of Galvanostatic charge/discharge curves of the flexible aqueous LIB before and after 100 cycle at a current density of $0.5 \mathrm{~A} \mathrm{~g}^{-1}$.

\section{Conclusion}

In summary, continuous composite fiber electrodes are fabricated using a simple and scalable method by online modifying direct-spun CNT fibers. The active materials, $\mathrm{LiFePO}_{4}$ and $\mathrm{LiTi}_{2}\left(\mathrm{PO}_{4}\right)_{3}$, are in close contact with CNTs, resulting in composite fibers with good electrochemical performance in aqueous LIBs. The 
composite fibers were further assembled into flexible fiber-shaped aqueous lithium-ion battery with high performance. High specific capacity of $29.1 \mathrm{mAh} \mathrm{g}^{-1}$ at a current density of $0.25 \mathrm{~A} \mathrm{~g}^{-1}$ can be obtained. The battery has a high energy density of $30.12 \mathrm{Wh} \mathrm{kg}^{-1}$. This research greatly expands the fabrication of composite fiber electrodes for wearable devices.

\section{Acknowledgments}

This work was supported by funding from the National Natural Science Foundation of China (Grant No.51502045), Guangzhou Science and Technology Program (Grant No.201607010141), the Nansha Science and Technology Program (Grant No. 2017CX012), and Australian Research Council under the Discovery Early Career Researcher Award (DECRA, No. DE170100871).

\section{References}

1. M. Yousaf, H. T. H. Shi, Y. S. Wang, Y. J. Chen, Z. M. Ma, A. Y. Cao, H. E. Naguib and R. P. S. Han, Adv. Energy Mater., 2016, 6, 1600490.

2. X. C. Gui, J. Q. Wei, K. L. Wang, A. Y. Cao, H. W. Zhu, Y. Jia, Q. K. Shu and D. H. Wu, Adv. Mater., 2010, 22, 617.

3. B. Liu, J. Zhang, X. F. Wang, G. Chen, D. Chen, C. W. Zhou and G. Z. Shen, Nano Lett., 2012, 12, 3005.

4. L. B. Hu, M. Pasta, F. La Mantia, L. F. Cui, S. Jeong, H. D. Deshazer, J. W. Choi, S. M. Han and Y. Cui, Nano Lett., 2010, 10, 708.

5. L. B. Hu, F. La Mantia, H. Wu, X. Xie, J. McDonough, M. Pasta and Y. Cui, Adv. Energy Mater., 2011, 1, 1012.

6. S. Y. Chew, S. H. Ng, J. Z. Wang, P. Novak, F. Krumeich, S. L. Chou, J. Chen and H. K. Liu, Carbon, 2009, 47, 2976.

7. X. F. Li, J. L. Yang, Y. H. Hu, J. J. Wang, Y. L. Li, M. Cai, R. Y. Li and X. L. Sun, J. Mater. Chem., 2012, 22, 18847.

8. Q. Huang, D. Wang and Z. Zheng, Adv. Energy Mater., 2016, 6, 1600783.

9. $\quad$ S. T. Senthilkumar, Y. Wang and H. Huang, J. Mater. Chem. A, 2015, 3, 20863.

10. Y. Zhang, Y. Zhao, J. Ren, W. Weng and H. S. Peng, Adv. Mater., 2016, 28, 4524.

11. T. Lv, Y. Yao, N. Li and T. Chen, Nano Today, 2016, 11, 644.

12. J. J. Vilatela and R. Marcilla, Chem. Mater., 2015, 27, 6901.

13. J. Ren, L. Li, C. Chen, X. Chen, Z. Cai, L. Qiu, Y. Wang, X. Zhu and H. Peng, Adv. Mater., 2013, 25, 1155. 
14. H. Lin, W. Weng, J. Ren, L. Qiu, Z. Zhang, P. Chen, X. Chen, J. Deng, Y. Wang and H. Peng, Adv. Mater., 2014, 26, 1217.

15. J. Ren, Y. Zhang, W. Bai, X. Chen, Z. Zhang, X. Fang, W. Weng, Y. Wang and H. Peng, Angew. Chem., Int. Ed., 2014, 53, 7864.

16. Y. Zhang, Y. Wang, L. Wang, C. M. Lo, Y. Zhao, Y. Jiao, G. Zheng and H. Peng, J. Mater. Chem. A, 2016, 4, 9002.

17. N. Behabtu, C. C. Young, D. E. Tsentalovich, O. Kleinerman, X. Wang, A. W. K. Ma, E. A. Bengio, R. F. Ter Waarbeek, J. J. De Jong, R. E. Hoogerwerf, S. B. Fairchild, J. B. Ferguson, B. Maruyama, J. Kono, Y. Talmon, Y. Cohen, M. J. Otto and M. Pasquali, Science, 2013, 339, 182.

18. M. Zhang, K. R. Atkinson and R. H. Baughman, Science, 2004, 306, 1358.

19. K. Koziol, J. Vilatela, A. Moisala, M. Motta, P. Cunniff, M. Sennett and A. Windle, Science, 2007, 318, 1892.

20. H. Kim, J. Hong, K. Y. Park, H. Kim, S. W. Kim and K. Kang, Chem. Rev., 2014, 114, 11788.

21. X. H. Zhong, Y. L. Li, Y. K. Liu, X. H. Qiao, Y. Feng, J. Liang, J. Jin, L. Zhu, F. Hou and J. Y. Li, Adv. Mater., 2010, 22, 692.

22. X. Dong, L. Chen, X. Su, Y. Wang and Y. Xia, Angew. Chem., Int. Ed., 2016, 55, 7474.

23. Y. Zhao, Y. Zhang, H. Sun, X. Dong, J. Cao, L. Wang, Y. Xu, J. Ren, Y. Hwang, I. H. Son, X. Huang, Y. Wang and H. Peng, Angew. Chem., Int. Ed., 2016, 55, 14384.

24. J. Ren, Y. Zhang, W. Y. Bai, X. L. Chen, Z. T. Zhang, X. Fang, W. Weng, Y. G. Wang and H. S. Peng, Angew. Chem., Int. Ed., 2014, 53, 7864.

25. Y. Zhang, W. Y. Bai, J. Ren, W. Weng, H. J. Lin, Z. T. Zhang and H. S. Peng, J. Mater. Chem. A, 2014, 2, 11054.

26. K. Sun, D. A. Juarez, H. Huang, E. Jung and S. J. Dillon, J. Power Sources, 2014, 248, 582.

27. H. Wang, K. Huang, Y. Zeng, S. Yang and L. Chen, Electrochim. Acta, 2007, 52, 3280.

28. J. Y. Luo and Y. Y. Xia, Adv. Funct. Mater., 2007, 17, 3877.

29. J. Y. Luo, W. J. Cui, P. He and Y. Y. Xia, Nature Chem., 2010, 2, 760. 